\title{
Technology Usage, eHealth Literacy and Attitude Towards Connected Health in Caregivers of Paediatric Cancer
}

\author{
Emma Delemere \\ Dept. of Psychology \\ Maynooth University \\ Maynooth, Ireland \\ emma.delemere.2020@mumail.ie \\ ORCID: 0000-0003-1237-5566
}

\author{
Dr Rebecca Maguire (CPsychol.) \\ Dept. of Psychology \\ Maynooth University \\ Maynooth, Ireland \\ rebecca.maguire@mu.ie \\ ORCID: 0000-0002-0368-4626
}

\begin{abstract}
While Connected Health (CH) presents an attractive solution to supporting those with paediatric cancer within a burdened healthcare system, uptake has been limited in practice. This study explored the extent to which attitudes towards $\mathrm{CH}$ and the ability to identify evidence-based $\mathrm{CH}$ interventions could be predicted by technology usage and eHealth literacy for parents of children with cancer and their Health Care Providers (HCPs). A survey of 85 parents and HCPs was conducted consisting of measures of eHealth literacy, attitude towards online sources, electronic device/internet usage and evaluations of existing $\mathrm{CH}$ technologies. While respondents frequently interacted with online supports, $\mathrm{CH}$ use was limited $(30.8 \%)$. Multiple regression and t-test analyses were conducted to determine the relationship between technology usage and eHealth literacy on $\mathrm{CH}$ use, attitude and perceived quality. Positive attitudes towards $\mathrm{CH}$ and strong eHealth literacy skills were found, however, those who had not used $\mathrm{CH}$ had significantly lower eHealth literacy than those who had $(t(74)=2.08, p=.04$ (two-tailed). Further, eHealth Literacy and device use significantly impacted attitude $(F(3,75)=12.01$, $\mathrm{p}<.001)$ and trust in higher quality $\mathrm{CH}$ applications (F $(2,58)=3.87, p=.03)$. This suggests that eHealth literacy and device access play a crucial role in facilitating $\mathrm{CH}$ use for stakeholders in paediatric cancer. Consideration of how best to support those with differing eHealth literacy when developing CH technologies is needed to support effective employment in practice.
\end{abstract}

Keywords - Connected Health, Paediatric Cancer, eHealth Literacy, Attitude, Accessibility.

\section{INTRODUCTION}

Social distancing measures implemented in response to the Covid-19 pandemic have given rise to a digital revolution in healthcare [1]. Specifically, restrictions to in-person service delivery have led to a greater reliance on digital technologies to support patients [2]. One such area of digitalisation is connected health $(\mathrm{CH})$, an umbrella term referring to the concepts of eHealth and mHealth, a mongst other technologies [3]. $\mathrm{CH}$ differs from other technologies in that it involves a two-way flow of information, where user data is gathered, analysed and returned in a manner that provides insight. $\mathrm{CH}$ may be of particular benefit to families impacted by paediatric cancer by providing support while reducing barriers to care [4]. However, research suggests low adherence and high attrition rates for $\mathrm{CH}$ use in practice generally [5], [6]

Funder: SFI Centre for Research Training in Advanced Networks for Sustainable Societies (ADVANCE) suggesting a clear need to increase engagement with these technologies [7].

Poor understanding [8] and lack of desire to use $\mathrm{CH}$ [9] has been noted among patients, however limited research has examined the reasons for this reluctance to engage with $\mathrm{CH}$. From a theoretical perspective, $\mathrm{CH}$ acceptance can be considered a form of behavioural intention, and as such a predictor of use [10]. While acceptance has been linked with experience and proficiency in technology [11], there is a need to exa mine further its role in facilitating $\mathrm{CH}$ use. An additional factor that may impact $\mathrm{CH}$ acceptance is eHealth literacy. eHealth literacy is the ability to locate, evaluate and apply health-based information pertaining to a specific concem from internet-based sources [12]. Positive associations between eHealth literacy and acceptance have been noted [10], [13], [14] with those with lower expectations of $\mathrm{CH}$ also having lower intentions to use [15]. eHealth literacy also impacts attitude towards $\mathrm{CH}$ for Health Care Providers (HCPs), with technological skills and comfort associated with greater digital usage [16]. While broad analysis of the impacts of attitude and eHealth Literacy have been conducted, no analysis of the effects of these factors within paediatric cancer has occumed to date.

HCPs play an essential role in $\mathrm{CH}$ implementation [17] and have been shown to mediate attitude development in patients [18]. However, HCPs a re unlikely to fully utilise these technologies in practice [10], [19]. Techno-centrist design may exacerbate this research-practice gap by removing stakeholders from the design process [20], [21]. To mitigate this, research efforts have shifted to a bottom-up approach in which $\mathrm{CH}$ use for individual stakeholders is the primary subject of a nalysis [19]. Further analysis of stakeholder needs pertaining to $\mathrm{CH}$ in paediatric cancer is required to ensure its effective implementation for this cohort.

The use of mHealth, a form of $\mathrm{CH}$, is growing rapidly within paediatric cancer, with high availability and varied quality [22]. Covid-19 responses by the United States Food and Drug Administration (FDA) further exacerbated this quality discrepancy through easing mHealth restrictions to expand access [23]. Additionally, mHealth tools developed by researchers and based in scientific evidence are rarely shared with the public [24]. As such patients and HCPs have difficulties accessing appropriate, high quality and relevant health content [25], [26]. Analysis of safety concerns in 
consumer-facing health apps found eighty individual safety concerns across the literature, from inaccurate or insufficient information to failure to respond to high-risk information [27]. Gaps highlighted included a lack of stakeholder involvement and poor evidentiary support. This suggests a need for additional analysis of mHealth supports in this space to ensure their efficacy.

As healthcare systems are increasingly burdened, $\mathrm{CH}^{\mathrm{s}}$ efficiencies and cost savings present an attractive solution. While positive impacts of $\mathrm{CH}$ have been noted, barriers such as attitude, eHealth literacy and comfort with technology may impact uptake. Further, stakeholders demonstrate skills deficits in identifying effective, relevant, and evidence-based $\mathrm{CH}$ technologies. This presents risks both for impact and future uptake. An analysis of the barriers or facilitators to use is needed to support greater uptake of $\mathrm{CH}$ within paediatric cancer. As such, examination of the role of eHealth literacy and technology usage on the ability to identify evidence-based $\mathrm{CH}$ interventions is required. This study seeks to a naly se the relationship between technology usage, eHealth literacy and attitude towards $\mathrm{CH}$ for parents of children with cancer and their HCPs. Secondly, we aim to examine the relationship between eHealth literacy, technology use and the ability to identify evidence-based $\mathrm{CH}$ interventions for parents and healthcare providers.

\section{METHOD}

\section{A. Participants}

A sample of parents/caregivers of paedia tric cancer and HCPs were recruited to take part in the study between October 2020 and March 2021. For HCPs, eligibility criteria included being qualified as an HCP with at least one year's experience working with children. For parents/caregivers, eligibility criteria consisted of having a child (aged 0-18) with cancer who was at least six months post-diagnosis but less than five years from active treatment. Recruitment was conducted through sharing invitations to participate on social media and circulating among support services and non-governmental associations in the paediatric cancer space. Full ethical approval for this study was obtained through the Maynooth University ethics board (reference number: 2408299). In addition, full informed consent was obtained from all participants.

\section{B. Measures}

The following information was collected from participants using an online survey:

1) Demographic Information: Brief demographic information was obtained, including age, gender, marital status and ethnicity. For parents, the child age, diagnosis and stage in the treatment/survivorship trajectory was collected.

2) Electronic Device/Internet Usage. Electronic device and internet usage for health was measured using an adapted version of the Health Information National Trends Survey (HINTS) [14]. Three questions were asked pertaining to internet use through different technologies, devices used, and online health behaviours completed in the past year.

3) eHealth Literacy: The eHealth literacy eScale (eHEALS) [12], was used to measure participants' eHealth Literacy. The eHEALS is an 8 -item measure of knowledge, skills and comfort at finding, evalua ting and a pplying eHealth information to health concerns. Cronbach's alpha was .92 suggesting strong reliability.

4) eHealth Attitude: The 5-item computer interest subscale of the adapted Attitudes Toward Computer/Intemet Questionnaire (ATC/IQ) [28] [29] was utilised to measure attitudes towards eHealth. Cronbach's alpha was 0.65 suggesting an acceptable level of reliability within the scale.

5) Application (App) evaluation: A simple Likert scale from 1 (Strongly disagree) to 5 (Strongly agree) was developed to measure participants' self-reported trust in a number of $\mathrm{CH}$ smartphone apps. These apps were selected based on systematic searches of the Google Play and the Apple App Store in September 2020. To be included in the analysis, apps were required to provide a $\mathrm{CH}$ intervention for parents or children affected by paediatric cancer. Extending on a previous content analysis where a total of 1316 apps were found to meet inclusion criteria, those apps with the greatest and least number of behaviour change techniques (BCTs) were selected for use in this study. BCTs are observable and replicable components of interventions that effectively change behaviour, with interventions including BCTs more likely to be effective [30]. BCTs Taxonomy, Version 1 (BCTv1) was used for content analysis [31]. The BCTTV 1 consists of 93 individual BCTs across 16 domains. The presence or absence of each BCT for each app was examined and a one scored if the technique was present. Scores were then summed to determine an apps total volume of BCTs. The three applications with the greatest and lea st number of BCTs were selected for inclusion. Apps included in the present analysis targeted symptom tracking and management $(n=4)$ and communication with HCPs $(n=2)$. Low BCT apps included on average 1.7 BCTs compared to high BCT apps, which had 16.7 BCTs on average.

\section{Data Analysis}

Data were analysed using the Statistical Package for Social Sciences (SPSS). Multiple regression analyses were conducted to assess the influence of eHealth literacy and Internet/Device usage on ATC/IQ. To determine the relationship between technology usage, eHealth literacy and attitude toward $\mathrm{CH}$ and participants self-reported trust, likelihood to use and perceived quality of $\mathrm{CH}$ apps, multiple regression analyses were conducted. Preliminary analyses were conducted to ensure no violation of the assumptions of normality, linearity, multicollinearity and homosceda sticity. Two blocks of predictor variables were employed for each multiple regression model, internet/device usage and eHealth Literacy. The Pearson product-moment correlation coefficient was used to examine the relationship between eHealth literacy and scientific evidence and trust in high and low BCT apps. To determine the impact of eHealth Literacy on past use of $\mathrm{CH}$ for HCPs and parents, an independent samples t-test was conducted.

\section{RESULTS}

\section{A. Participant Characteristics}

Participants were primarily a ged $35-44(44.6 \%, \mathrm{n}=25)$, resided in Ireland $(64.6 \%, \mathrm{n}=53)$, female $(89.4 \%, \mathrm{n}=76)$, married $(70.6 \%, n=60)$ and lived in a large town or city $(44.7 \%, n=38)$. For parents of children with cancer, diagnoses included Acute 
Lymphoblastic Lymphoma (ALL, 40.8\%), brain or spinal cord cancer $(10.2 \%)$ or a nother cancer $(12.2 \%)$. Children were primarily aged under five $(36.4 \%)$ or between six and ten $(34.5 \%)$ and had finished active treatment for over one year $(27.1 \%)$, though a variety of treatment/survivorship stages were noted.

TABLE 1: Demographic Information

\begin{tabular}{|c|c|c|c|c|c|c|c|}
\hline & \multicolumn{6}{|c|}{ Participant Type } \\
\hline & & \multicolumn{2}{|c|}{$\begin{array}{l}\text { Parents } \\
(n=57)\end{array}$} & \multicolumn{2}{|c|}{$\begin{array}{l}H C P s \\
(n=28)\end{array}$} & \multicolumn{2}{|c|}{$\begin{array}{c}\text { Total } \\
(n=85)\end{array}$} \\
\hline & & $\mathrm{n}$ & $\%$ & $\mathrm{n}$ & $\%$ & $\mathrm{n}$ & $\%$ \\
\hline \multirow[t]{6}{*}{ Age } & $18-24$ & 2 & 4.9 & $\overline{0}$ & 0 & 2 & 3.6 \\
\hline & $25-34$ & 6 & 14.6 & 7 & 46.7 & 13 & 23. \\
\hline & $35-44$ & 22 & 53.7 & 3 & 20.0 & 25 & 44. \\
\hline & $45-54$ & 9 & 22.0 & 3 & 20.0 & 12 & 21. \\
\hline & $55-64$ & 1 & 2.4 & 2 & 13.3 & 3 & $\overline{5.4}$ \\
\hline & $65+$ & 1 & 2.4 & 0 & 0.0 & 1 & 1.8 \\
\hline \multirow[t]{2}{*}{ Gender } & Male & 3 & 5.3 & 6 & 21.4 & 9 & 10. \\
\hline & Female & 54 & 94.7 & 22 & 78.6 & 76 & 89. \\
\hline \multirow[t]{3}{*}{$\begin{array}{l}\text { Habitu } \\
\text { ation }\end{array}$} & $\begin{array}{c}\text { Rural }(<5,000 \\
\text { inhabitants })\end{array}$ & 19 & 33.3 & 5 & 17.9 & 24 & $\begin{array}{r}28 . \\
2\end{array}$ \\
\hline & $\begin{array}{l}\text { Small Town } \\
(<10,000 \\
\text { inhabitants })\end{array}$ & 21 & 36.8 & $\overline{2}$ & 7.1 & 23 & $\begin{array}{r}27 . \\
1\end{array}$ \\
\hline & $\begin{array}{c}\text { Large town/City } \\
(>10,000 \\
\text { inhabitants })\end{array}$ & 17 & 29.8 & 21 & 75.0 & 38 & \\
\hline \multirow{5}{*}{$\begin{array}{l}\text { Marital } \\
\text { status }\end{array}$} & Married & 41 & 71.9 & 19 & 67.9 & 60 & 70. \\
\hline & Widowed & 1 & 1.8 & 1 & 3.6 & 2 & 2.4 \\
\hline & $\begin{array}{l}\text { Divorced/ } \\
\text { Separated }\end{array}$ & 2 & 3.5 & 1 & 3.6 & 3 & 3.5 \\
\hline & Cohabitating & 9 & 15.8 & 5 & 17.9 & 14 & 16. \\
\hline & Never married & 4 & 7.0 & 2 & 7.1 & 6 & 7.1 \\
\hline
\end{tabular}

\section{B. Electronic Device/Internet Usage}

Most respondents accessed the internet daily using computers $(61.5 \%)$, a mobile device $(92.3 \%)$ or $\mathrm{CH}(30.8 \%)$. However, $5.6 \%$ of parents only accessed the internet weekly. Smartphones were the most common device used within the past year by both groups (91.8\%). Tablet computers $(63.5 \%)$, wellness apps (48.2\%) and smart devices were also common (47.1\%). Participants engaged with an avera ge of 3 different technologies within the past year, with both group means relatively equal. Mean online health behaviours for HCPs were slightly higher $(m=6.12)$ than parents $(m=5.55)$. HCPs also completed more $\mathrm{CH}$ activities a cross the past year (mean $=2.32)$ in comparison to parents (mean=1.92).

To determine the impact of eHealth Literacy on past use of $\mathrm{CH}$ for HCPs and parents, an independent samples t-test was conducted. Past $\mathrm{CH}$ use was determined based on answers to the technology/device use questions pertaining specifically to $\mathrm{CH}$ use. There was a significant difference in scores for those who had used $\mathrm{CH}(\mathrm{M}=32.6, \mathrm{SD}=6.9)$ and those who had $\operatorname{not}(\mathrm{M}=29.1, \mathrm{SD}=7.4 ; \mathrm{t}(74)=2.08, \mathrm{p}=.04$, two-tailed $)$. The magnitude in differences in the means (mean difference $=3.47$, 95\% Cl:.145-6.81) was moderate (eta squared =.06). An independent samples t-test was also conducted to compare eHealth Literacy scores across the two participant groups. No significant difference was found in scores between parents $(\mathrm{M}=29.98, \mathrm{SD}=6.37)$ and HCPs $(\mathrm{M}=32.6, \mathrm{SD}=8.7)$; $\mathrm{t}(74)=-$ $1.4, \mathrm{p}=.16$ (two-tailed).

\section{C. eHealth Literacy \& Attitudes}

Participants reported positive attitudes towards online sources with mean scores of 20.67. Parents $(m=21.05)$ were slightly more positive than HCPs $(m=19.92)$. The reverse was the case for eHealth Literacy with HCPs $(m=32.48)$ scoring higher than parents $(m=29.98)$, though both groups had good eHealth Literacy skills (see Table 2).

TABLE 2: Mean Device, Attitude and eHealth literacy

\begin{tabular}{|c|c|c|c|c|c|}
\hline & \multicolumn{3}{|c|}{ Participant Type } \\
\hline & & & \multirow{2}{*}{$\begin{array}{c}\begin{array}{c}\text { Parent } \\
(n=51)\end{array} \\
5.55\end{array}$} & \multirow{2}{*}{$\begin{array}{r}\begin{array}{r}H C P \\
(n=25)\end{array} \\
6.12\end{array}$} & \multirow{2}{*}{$\begin{array}{r}\text { All } \\
(n=76)\end{array}$} \\
\hline \multirow{4}{*}{$\begin{array}{l}\text { Electronic } \\
\text { Device/ } \\
\text { Internet } \\
\text { Usage }\end{array}$} & \multirow{2}{*}{$\begin{array}{l}\text { Mean actions } \\
\text { in past year }\end{array}$} & Mean & & & \\
\hline & & $\mathrm{SD}$ & 2.11 & 2.72 & 3.32 \\
\hline & \multirow{2}{*}{$\begin{array}{c}\text { Mean } \mathrm{CH} \\
\text { actions in the } \\
\text { past year }\end{array}$} & Mean & 1.98 & 2.32 & 2.10 \\
\hline & & $\mathrm{SD}$ & 0.77 & 0.98 & 0.86 \\
\hline \multirow[t]{2}{*}{ Attitude } & \multirow[t]{2}{*}{ ATC/IQ } & Mean & 21.05 & 19.92 & 20.67 \\
\hline & & $\mathrm{SD}$ & 3.22 & 3.30 & 3.27 \\
\hline \multirow{2}{*}{$\begin{array}{l}\text { eHealth } \\
\text { Literacy }\end{array}$} & \multirow[t]{2}{*}{ eHEALS } & Mean & 29.98 & 32.48 & 30.80 \\
\hline & & SD & 6.37 & 8.68 & 7.25 \\
\hline
\end{tabular}

Standard multiple regression was used to assess the impact of eHealth Literacy, device use and group on $\mathrm{CH}$ attitude as measured by the ACT/IQ. The total variance explained by the model as a whole was $30.6 \%, \mathrm{~F}(3,75)=12.01, \mathrm{p}<.001$. Significant unique contributions for both eHealth Literacy (beta $=-.377 ; \mathrm{p}<.001$ ) and device use (beta $=.356 ; \mathrm{p}<.001$ ) were found, with the largest single contribution to attitude from eLiteracy which explained $13 \%$ of the variance in the ACT/IQ scores, followed closely by device use at $11.3 \%$.

\section{Evaluation of CH applications with high and low BCTs}

Participants responded similarly to both high and low BCT $\mathrm{CH}$ apps regarding their scientific evidence and trust. Participant mean responses suggest both groups did not highly trust the quality of the apps for those with high or low BCTs.

TABLE 3: Evaluation of $\mathrm{CH}$ applications

\begin{tabular}{|c|c|r|r|r|r|}
\hline \multirow{2}{*}{\multicolumn{2}{|c|}{}} & \multicolumn{4}{|c|}{ BCT Measure } \\
\cline { 3 - 6 } \multicolumn{2}{|c|}{} & \multicolumn{1}{|c|}{ Scientific Evidence } & \multicolumn{2}{c|}{ Trust } \\
\hline $\begin{array}{c}\text { Participant } \\
\text { group }\end{array}$ & BCTs & \multicolumn{1}{|c|}{ High } & Low & \multicolumn{1}{c|}{ High } & Low \\
\hline $\begin{array}{c}\text { Parent } \\
(\mathrm{n}=43)\end{array}$ & Mean & 8.16 & 8.05 & 8.79 & 8.47 \\
\cline { 2 - 6 } & SD & 3.12 & 2.81 & 2.86 & 2.86 \\
\hline $\begin{array}{c}\text { HCP } \\
(\mathrm{n}=16)\end{array}$ & Mean & 9.00 & 8.63 & 9.94 & 9.25 \\
\cline { 2 - 6 } & SD & 3.246 & 2.029 & 3.043 & 1.81 \\
\hline \multirow{2}{*}{$\begin{array}{c}\text { Total } \\
(\mathrm{n}=59)\end{array}$} & Mean & 8.39 & 8.20 & 9.10 & 8.68 \\
\cline { 2 - 6 } & SD & 3.146 & 2.618 & 2.928 & 2.622 \\
\hline
\end{tabular}

The relationship between eHealth literacy and scientific evidence, and trust in high and low BCT apps was examined using Pearson product-moment correlation coefficient. There was a medium positive correlation between trust in High BCT apps and eHealth literacy $(\mathrm{r}=.41, \mathrm{n}=59, \mathrm{p}=.001)$ with high eHealth literacy associated with greater trust in High BCT apps. There was a small negative correlation between trust in 
low BCTs and device use ( $\mathrm{r}=.27, \mathrm{n}=59, \mathrm{p}=.04)$, with technology use associated with less trust in low BCT apps.

Several standard multiple regression analyses were conducted to assess the ability of eHealth Literacy and device use to predict trust and perceived degree of scientific evidence for $\mathrm{CH}$ applications with low or high volumes of BCTs. No significant effects for scientific evidence for low (F $(2,58)=2.81, \mathrm{p}=.07)$ or high BCTs $(\mathrm{F}(2,58)=1.17, \mathrm{p}=.321)$ or trust for apps with low BCTs $(\mathrm{F}(2,58)=1.9, \mathrm{p}=.15)$ was found. For trust in high BCT applications, the total variance explained by the model as a whole was $9 \%$, F $(2,58)=3.87$, $\mathrm{p}=.03$. Significant unique contributions for eHealth Literacy (beta=-.348; $\mathrm{p}=.008$ ) was found, explaining $11.8 \%$ of the variance in trust scores.

\section{DISCUSSION}

The present study sought to exa mine the impact of eHealth literacy, technology usage, and attitude towards $\mathrm{CH}$ and its use. Results suggest that while HCPs and parents frequently interact with technology and online supports for health, overall CH use was limited. Encoura gingly, positive attitudes and strong eHealth Literacy skills were found in both groups, with HCPs demonstrating slightly higher eHealth literacy and past $\mathrm{CH}$ use, while parents expressed more positive attitudes. Results suggest both eHealth literacy and past device usage play important roles in $\mathrm{CH}$ evaluation and use, with both contributing significantly to respondents' attitudes towards online sources and trust in high BCT apps. This suggests a key role for eHealth literacy and device access in supporting accurate evaluations of $\mathrm{CH}$ technologies and may facilitate effective use for stakeholders in paediatric cancer.

Our findings are broadly consistent with past literature. For example, the important role of technology familiarity on $\mathrm{CH}$ use is consistent with past findings suggesting technological comfort, self-efficacy and habit predict $\mathrm{CH}$ use [32]. Perhaps surprisingly, no associations between demographic factors were found in relation to $\mathrm{CH}$ use, attitudes, or eHealth literacy. This is somewhat contradictory to past findings [14] and may have been impacted by the smaller sample size and relative heterogeneity of the sample. Our results support past analyses that suggest a need to support and encourage patient and HCP comfort with technology to reduce negative $\mathrm{CH}$ attitudes [8]. We also highlight a lack of trust and perceived quality of $\mathrm{CH}$ apps for this population, suggesting a need for increased efforts to support the dissemination of such tools. Results highlight the important role of eHealth literacy in supporting effective $\mathrm{CH}$ evaluation and use. In the context of the high accessibility and mixed quality of $\mathrm{CH}$ tools [22], eHealth literacy appears to support parents and HCPs in identifying effective $\mathrm{CH}$. As such, these results suggest a need for efforts to support eHealth literacy for parents and HCPs. While the present analysis highlights eHealth literacy and encouraging device use as possible avenues to support $\mathrm{CH}$ uptake, additional efforts are required. Specifically, a need for expert analysis and dissemination of paediatric health apps through reputable and accessible sources has been noted [24], along with a need to incorporate $\mathrm{CH}$ technologies into training for HCPs to support use within clinical pathways [24], [33].

While the present analysis highlights parent and HCP willingness to engage with $\mathrm{CH}$, further exploration of the role $\mathrm{CH}$ may pose is needed. While the efficacy and acceptability of $\mathrm{CH}$ interventions for paedia tric cancer has been found [34], high attrition and poor adherence have been noted [35]. Further, variability in preferences towards digital service delivery has been noted [36], [37]. Within the present study low levels of trust in $\mathrm{CH}$ was noted for both HCPs and parents, though most had engaged in at least one $\mathrm{CH}$ activity. This may suggest a hesitancy towards technology-mediated interventions such as $\mathrm{CH}$ which requires additional analysis. For an intervention to be successfully deployed it must be acceptable to stakeholders. Additional analysis of stakeholder perspectives on $\mathrm{CH}$ and its role is needed to ensure its effective use and value for stakeholders. Further public and patient involvement and stakeholder co-design of $\mathrm{CH}$ is needed to support uptake. Future research should examine stakeholder perspectives on $\mathrm{CH}$ within the paediatric care pathway and include parents, HCPs and children themselves in the design of $\mathrm{CH}$ supports.

The present results highlight the need for additional decisional supports for parents and HCPs to support them in determining which $\mathrm{CH}$ tools may be of benefit. Many of the $\mathrm{CH}$ tools with empirical support are not publicly a vailable [24] creating difficulties in accessing higher quality supports [25], [26]. This absence of high-quality $\mathrm{CH}$ is particularty concerning when considered in the context of the high volume of freely available non-evidence-based $\mathrm{CH}$ on the market. This environment presents significant challenges to stakeholders in determining whether a $\mathrm{CH}$ app may be effective for their family. While the present analysis lends support to the importance of eHealth literacy in determining $\mathrm{CH}$ quality, analysis of factors which may support stakeholder decision making in this context is required. Future research should consider how best to engage with parents, HCPs and other key stakeholder to determine how to support decision making around $\mathrm{CH}$ use.

There are several limitations to the present study. Notably, the difficulties with participant recruitment and retention, with some respondents electing not to complete the BCT section of the survey, meaning that the present analysis is somewhat underpowered. Additionally, due to the constraints of the Covid-19 pandemic, participant recruitment occurred online only. As a result, device use and internet access may be higher in this sample due to the sampling methods employed. Additional efforts to examine eHealth literacy for hard-toreach populations is needed. A further limitation is the timing of the present study. As recruitment occurred during covid-19, the associated increased use of remote service delivery methods may have impacted attitudes and device use.

\section{CONCLUSION}

In conclusion, this study has highlighted the importance of eHealth Literacy and device use on $\mathrm{CH}$ for HCPs and parents of children with cancer. While high device use and online health behaviours were suggested, lower use of $\mathrm{CH}$ was found. Further, respondents did not rate $\mathrm{CH}$ apps shown as highly trustworthy or evidence-based, indicating a skepticism towards such tools. As such, there is a clear need for efforts to support eHealth Literacy and comfort in device use to aid $\mathrm{CH}$ adoption within paediatric cancer. The present analysis also suggests a need for technology developers to consider the eHealth Literacy or device familiarity required by users to successfully engage with $\mathrm{CH}$ tools. By considering those with lesser eHealth Literacy or device use in the development of $\mathrm{CH}$ through user input in design, increased accessibility and engagement may be attained. Increased cooperation between psychological sciences, technology developers and end-users 
is needed to ensure a lignment between technological a dvances and effective interventions for those seeking support [38]. Through this, a more significant societal impact may be attained through increased effective usage of $\mathrm{CH}$.

\section{ACKNOWLEDGMENT}

The authors would like to express their thanks to all who took part in the survey for their time and insight.

\section{REFERENCES}

[1] S. Keesara, A. Jonas, and K. Schulman, "Covid-19 and Health Care's Digital Revolution," N. Engl. J. Med., vol. 382, no. 23, p. e82, Jun. 2020, doi: 10.1056/nejmp2005835.

[2] S. M. Badawy and A. Radovic, "Digital Approaches to Remote Pediatric Health Care Delivery During the COVID-19 Pandemic: Existing Evidence and a Call for Further Research," JMIR Pediatr. Parent., vol. 3, no. 1, p. e20049, Jun.2020, doi: 10.2196/20049.

[3] J. K. Iglehart, "Connected health: Emerging disruptive technologies," Health Affairs, vol. 33, no. 2. p. 190, 2014, doi: 10.1377/hlthaff.2014.0042.

[4] Y. Leykin, S. M. Thekdi, D. M. Shumay, R. F. Muñoz, M. Riba, and L. B. Dunn, "Internet interventions for improving psychological well-being in psycho-oncology: Review and recommendations," Psycho-Oncology, vol. 21, no. 9. Psychooncology, pp. 1016-1025, Sep. 2012, doi: 10.1002/pon.1993

[5] C. Vandelanotte et al., "Past, Present, and Future of eHealth and mHealth Research to Improve Physical Activity and Dietary Behaviors," J. Nutr. Educ. Behav., vol. 48, no. 3, pp. 219-228.el, Mar. 2016, doi: 10.1016/j.jneb.2015.12.006.

[6] S. Michie, L. Yardley, R. West, K. Patrick, and F. Greaves, "Developing and evaluating digital interventions to promote behavior change in health and health care: Recommendations resulting from an international workshop," Journal of Medical Internet Research, vol. 19, no. 6. Journal of Medical Internet Research, p.e232, Jun. 29, 2017, doi: 10.2196/jmir.7126.

[7] O. Perski, A. Blandford, R. West, and S. Michie, "Conceptualising engagement with digital behaviour change interventions: a systematic review using principles from critical interpretive synthesis," Translational Behavioral Medicine, vol. 7, no. 2. Springer New York LLC, pp. 254-267, Jun. 01, 2017, doi: 10.1007/s13142-016-0453-1

[8] D. Haluza, M. Naszay, A. Stockinger, and D. Jungwirth, "Prevailing opinions on connected health in Austria: Results from an online survey," Int. J. Environ. Res. Public Health, vol. 13, no. 8, Aug. 2016, doi: 10.3390/ijerph13080813.

[9] M. del Río Carral, A. Schweizer, A. Papon, and M. SantiagoDelefosse, "Connected objects and health applications: Exploratory study on attitudes, use (or non-use) and contexts of use," Prat. Psychol., vol. 25, no. 1, pp. 1-16, Mar. 2019, doi: 10.1016/j.prps.2018.05.001.

[10] S. Hennemann, M. E. Beutel, and R. Zwerenz, "Ready for eHealth? Health Professionals' Acceptance and Adoption of eHealth Interventions in Inpatient Routine Care," J. Health Commun., vol. 22 , no. 3, pp. 274-284, Mar. 2017, doi: 10.1080/10810730.2017.1284286.

[11] F. Hofer and D. Haluza, "Are Austrian practitioners ready to use medical apps? Results of a validation study," BMC Med. Inform. Decis. Mak., vol. 19, no. 1, Apr.2019, doi: 10.1186/s12911-0190811-2.

[12] C. D. Norman and H. A. Skinner, "eHEALS: The eHealth literacy scale," J. Med. Internet Res., vol. 8, no. 4, p. e27, Nov. 2006, doi: 10.2196/jmir.8.4.e27.

[13] C. L. Donovan, C. Poole, N. Boyes, J. Redgate, and S. March, "Australian mental health worker attitudes towards cCBT: What is the role of knowledge? Are there differences? Can we change them?," Internet Interv., vol. 2, no. 4, pp. 372-381, Nov. 2015, doi: 10.1016/j.invent.2015.09.001.

[14] B. Tennant et al., "eHealth literacy and Web 2.0 health information seeking behaviors among baby boomers and older adults," J. Med. Internet Res., vol. 17, no. 3, p. e70, Mar. 2015, doi: 10.2196/jmir.3992

[15] L. Liu, A. Miguel Cruz, A. Rios Rincon, V. Buttar, Q. Ranson, and
D. Goertzen, "What factors determine therapists' acceptance of new technologies for rehabilitation-a study using the Unified Theory of Acceptance and Use of Technology (UTAUT)," Disabil. Rehabil., vol. 37, no. 5, pp. 447-455, Mar. 2015, doi: 10.3109/09638288.2014.923529.

[16] J. Konttila et al., "Healthcare professionals' competence in digitalisation: A systematic review," Journal of Clinical Nursing, vol. 28, no. 5-6. Blackwell Publishing Ltd, pp. 745-761, Mar. 01, 2019, doi: 10.1111/jocn. 14710 .

[17] C. Eichenberg, C. Wolters, and E. Brähler, "The Internet as a Mental Health Advisor in Germany-Results of a National Survey," PLoS One, vol. 8, no. 11, p. e79206, Nov. 2013, doi: 10.1371/journal.pone.0079206

[18] S. Y. Gun, N. Titov, and G. Andrews, "Acceptability of internet treatment of anxiety and depression," Australas. Psychiatry, vol. 19, no. 3, pp. 259-264, Jun. 2011, doi: $10.3109 / 10398562.2011 .562295$.

[19] C. Granja, W. Janssen, and M. A. Johansen, "Factors determining the success and failure of ehealth interventions: Systematic review of the literature," Journal of Medical Internet Research, vol. 20, no. 5. Journal of Medical Internet Research, p. e10235, May 01, 2018, doi: 10.2196/10235.

[20] C. Frauenberger, J. Good, G. Fitzpatrick, and O. S. Iversen, "In pursuit of rigour and accountability in participatory design," Int. $J$. Hum. Comput. Stud., vol. 74, pp. 93-106, Feb. 2015, doi: 10.1016/j.jhcs.2014.09.004.

[21] K. Biggs, P. Lowe, J. Walsh, and K. Lagios, "Audit of a sexual health website email link for general practitioners," International Journal of STD and AIDS, vol.21, no. 1. Int J STD AIDS, pp. 6062, Jan. 2010, doi: 10.1258/ijsa.2009.009192.

[22] S. Leigh and S. Flatt, "App-based psychological interventions: Friend or foe?," Evid. Based. Ment. Health, vol. 18, no. 4, pp.9799, Nov. 2015, doi: 10.1136/eb-2015-102203.

[23] U.S. Department of Health and Human Services, Food and Drug Administration, Center for Devices and Radiological Health (CDRH), and Office of Product Evaluation and Quality (OPEQ), "Enforcement Policy for Digital Health Devices For Treating Psychiatric Disorders During the Coronavirus Disease 2019 (COVID-19) Public Health Emergency Guidance for Industry and Food and Drug Administration Staff," 2020. Accessed: Jan. 07, 2021. [Online]. Available: https://www.fda.gov/regulatory-

[24] A. M. Psihogios, C. Stiles-Shields, and M. Neary, "The Needle in the Haystack: Identifying Credible Mobile Health Apps for Pediatric Populations during a Pandemic and beyond," J. Pediatr. Psychol., vol. 45, no. 10, pp. 1106-1113, Nov. 2020, doi: 10.1093/jpepsy/jsaa094.

[25] C. Knapp, V. Madden, H. Wang, P. Sloyer, and E. Shenkman, "Internet use and eHealth Literacy of low-income parents whose children have special health careneeds," J. Med. Internet Res, vol. 13, no. 3, Jul. 2011, doi: 10.2196/jmir.1697.

[26] S. Rathnayake and A. Senevirathna, "Self-reported eHealth literacy skills among nursing students in Sri Lanka: A crosssectional study," Nurse Educ. Today, vol. 78, pp. 50-56, Jul. 2019, doi: 10.1016/j.nedt.2019.04.006.

[27] S. Akbar, E. Coiera, and F. Magrabi, "Safety concerns with consumer-facing mobile health applications and their consequences: a scoping review," J. Am. Med.Informatics Assoc., vol. 27, no. 2, pp. 330-340, Feb. 2020, doi: 10.1093/jamia/ocz175.

[28] G. G. Bear, H. C. Richards, and P. Lancaster, "Attitudes toward Computers: Validation of a Computer Attitudes Scale," J. Educ. Comput. Res., vol. 3, no. 2, pp. 207-218, May 1987, doi: 10.2190/1dyt-1jej-t8j5-1yc7.

[29] N. G. Choi and D. M. Dinitto, "The digital divide among lowincome homebound older adults: Internet use patterns, ehealth literacy, and attitudes toward computer/internet use," J. Med. Internet Res., vol. 15, no. 5, p. e2645, May 2013, doi: 10.2196/jmir.2645.

[30] D. Morrison et al., "Digital asthma self-management interventions: A systematic review," Journal of Medical Intemet Research, vol. 16, no. 2. Journal of Medical Internet Research, p. e51, Feb. 18, 2014, doi: 10.2196/jmir. 2814.

[31] S. Michie et al., "The Behavior Change Technique Taxonomy (v1) of 93 Hierarchically Clustered Techniques: Building an International Consensus for the Reporting of Behavior Change Interventions," Ann. Behav. Med., vol.46, no. 1, pp. 81-95, Aug. 2013, doi: 10.1007/s12160-013-9486-6.

[32] H. Hah, D. Goldin, and S. Ha, "The association between 
willingness of frontline care providers' to adaptively use telehealth technology and virtual service performance in provider-toprovider communication: Quantitative study," J. Med. Intemet Res., vol. 21, no. 8, p. e15087, Aug. 2019, doi: 10.2196/15087.

[33] J. V. Lavigne, M. Feldman, and K. M. Meyers, "Screening for mental health problems: Addressing the base rate fallacy for a sustainable screening program in integrated primary care," $J$. Pediatr. Psychol., vol.41, no. 10, pp. 1081-1090, Nov. 2016, doi: 10.1093/jpepsy/jsw048.

[34] E. Delemere and R. Maguire, "The role of Connected Health technologies in supporting families affected by paediatric cancer: A systematic review," Psychooncology., p. pon.5542, Sep. 2020, doi: $10.1002 /$ pon.5542.

[35] K. S. Canter, G. Vega, A. P. Ramirez, J. A. Deatrick, and A. E. Kazak, "Strategies for Successful Recruitment and Retention of Parents in Pediatric Psychosocial eHealth Interventions: A
Qualitative Study in Pediatric Oncology," J. Pediatr. Psychol, vol. 45, no. 5, pp. 530-539, Jun. 2020, doi: 10.1093/jpepsy/jsaa013.

[36] N. Heynsbergh, M. Botti, L. Heckel, and P. M. Livingston, "Caring for the person with cancer and the role of digital technology in supporting carers," Support. Care Cancer, vol. 27, no. 6, pp. 22032209, Jun. 2019, doi: 10.1007/s00520-018-4503-8.

[37] M. Hashemi, A. Irajpour, and F. Taleghani, "Caregivers needing care: the unmet needs of the family caregivers of end-of-life cancer patients," Support. Care Cancer, vol. 26, no. 3, pp. 759-766, Mar. 2018, doi: 10.1007/s00520-017-3886-2.

[38] F. Taj, M. C. A. Klein, and A. van Halteren, "Digital Health Behavior Change Technology: Bibliometric and Scoping Review of Two Decades of Research," JMIR Mhealth Uhealth 2019;7(12)e13311 https//mhealth.jmir.org/2019/12/e13311/, vol. 7, no. 12, p. e13311, Dec. 2019, doi: 10.2196/13311. 